\title{
Article
}

\section{Optimizing ofl recovery factor by horizontal and vertical infill drilling using streamline simulation in an Iranian oil reservoir}

Dailami, Keyvan, Nasriani, Hamid Reza, Sajjadi, Seyed Adib and Alizadeh, Naser

Available at http://clok.uclan.ac.uk/17198/

Dailami, Keyvan, Nasriani, Hamid Reza ORCID: 0000-0001-9556-7218, Sajjadi, Seyed Adib and Alizadeh, Naser (2017) Optimizing oil recovery factor by horizontal and vertical infill drilling using streamline simulation in an Iranian oil reservoir. Energy Sources, Part A: Recovery, Utilization, and Environmental Effects . pp. 1-8. ISSN 1556-7036

It is advisable to refer to the publisher's version if you intend to cite from the work. http://dx.doi.org/10.1080/15567036.2011.608777

For more information about UCLan's research in this area go to http://www.uclan.ac.uk/researchgroups/ and search for <name of research Group>.

For information about Research generally at UCLan please go to http://www.uclan.ac.uk/research/

All outputs in CLoK are protected by Intellectual Property Rights law, including Copyright law. Copyright, IPR and Moral Rights for the works on this site are retained by the individual authors and/or other copyright owners. Terms and conditions for use of this material are defined in the policies page. 


\title{
Optimizing Oil Recovery Factor by horizontal and vertical Infill Drilling Using Streamline Simulation in an Iranian Oil Reservoir
}

\author{
Keyvan Dailami ${ }^{1}$, Hamid Reza Nasriani ${ }^{2}$, Seyed Adib Sajjadi ${ }^{1}$, Naser Alizadeh $^{3}$ \\ ${ }^{1}$ Islamic Azad University, Omidieh Branch, Omidieh, Iran. Keyvan_dailami_oil@yahoo.com \\ ${ }^{2}$ School of Engineering, Faculty of Science and Technology, University of Central \\ Lancashire, Preston, United Kingdom \\ ${ }^{3}$ Amirkabir University of Technology (Tehran Polytechnic), Tehran, Iran
}

\begin{abstract}
Although nowadays finite difference simulators have many advantages for reservoir engineers to predict reservoirs in 3 dimensions, they have some disadvantages; such as spending much run time for complex fields with several thousand grids which by using Streamline simulation, the run time was decreased a lot. In this paper, first a brief summary of streamline simulation and its uniqueness applications were discussed and then an Iranian oil reservoir as a case study was simulated by using FrontSim streamline simulator, then besides testing the results of Sayyafzadeh et al (2010) to find the location of infill wells, the most suitable locations for infill drilling were selected, after that, vertical and horizontal infill wells were investigated and overally 34 scenarios were tested by using Streamline simulation method and FrontSim software, finally the results of simulation and testing infill drilling scenario shows significant increasing in field oil production and field oil recovery factor, approximately 13\%, and also reduction field water cut. In addition, distinguishing fractures or faults, well's drainage area and understanding that how much injectors affect the field oil production are other benefits of Streamline simulation method. The Novelty of this paper was to study the effects of horizontal infill wells and comparing the results between horizontal and vertival infill drilling using streamline simulation.
\end{abstract}

Key words: Recovery Factor, Streamline Simulation, Infill Drilling, horizontal well, vertical well, Water Flooding

\section{Introduction}


In order to show more realistic conditions of geology and fluid flow patterns, reservoir models are becoming more complex recently, so using streamline method instead of finite difference method for large scale reservoir simulation has some advantages such as quickness, less computer memory requirement and good convergence (Hou et al., 2007; Samier et al., 2001) Streamline-based flow simulation provides new flow information ( i.e. well connectivity, drainage volume, well allocation factors) that cannot be derived from conventional simulation (Thiele et al., 2001). Therefore it is particularly effective in solving large, geologically complex and heterogeneous systems and this technology has been accepted as an effective, new and complementary technology with high computational efficiency which solve finite difference's problem even for modeling with tiny grids. The streamline simulation method solves a 3D problem by decoupling it into a series of 1D problems along a streamline. Modeling fluid flow and transport using streamline and streamtubes dates back to the seminal works of several authors. The streamline methods use concepts from particle tracking to define pathlines in 3D space (Gupta et al., 2007). Production from hydrocarbon reservoirs requires precise determination of reservoir fluid properties along with their positive impact on real reservoir performance evaluation and fluid in place volume calculation (Nasriani et al., 2015a; Nasriani et al., 2015b). Pressure maintenance and different fluid phase injection are the common practices used in the oil and gas fields to alleviate the negative impact of reservoir depletion on hydrocarbon recovery (Zareenejad et al., 2015; Nassiri et al., 2015; Nasriani et al., 2014; Kalantariasi et al., 2013).

In this paper, after specifying the location of infill wells by using streamline simulation, 6 scenarios ( 5 horizontal +1 vertical ) were defined for each infill well and then based on their results 10 scenarios were investigated by considering four infill wells vertically or horizontally in a model, totally 34 scenarios were inquired and were investigated by Streamline simulation to optimize the oil recovery factor for an Iranian oil reservoir. The Novelty of this paper was 
to study the effects of horizontal infill wells and comparing the results between horizontal and vertival infill drilling using streamline simulation.

\section{Base model}

The base model which is used in this study is one of the developed and undersaturated Iranian oil reservoirs which produces under aquifer drive.Two aquifers on the East-North and EastSouth of the reservoir prepare very good water drive and 3D - 3 phases streamline simulator "FrontSim", has been used to make its dynamic model. FrontSim is one of the modules of Eclipse (GeoQuest) software of Schlumberger Company. The Cartesian model has 35 grids in $\mathrm{X}$ and $\mathrm{Y}$ directions respectively and 5 layers in $\mathrm{Z}$ direction, so it has 6125 grids totally which arranged in Corner Point gridding method. Static and dynamic parameters for rock and fluid were defined in the model. Figure 1 shows the 3D model of the base model.

Simulation to predict for 3683 days after 365 days of production history was done.9 producers and 3 water injectors which all of them are active during production history, are considered. Water injection is one of the most applied secondary recovery methods in the world and Streamline Simulation is particularly interesting in this type of application. For economical production, some limitations for all scenarios were defined, such as: maximum water cut is 0.9 and maximum water injection rate for every injector is $6000 \mathrm{STB} / \mathrm{Day}$ and maximum oil rate for every producer is 2000 STB/Day.

\section{Methodology}

The objective of this study is to develop a methodology for one of Iranian oil fields by using Streamline simulation and defining infill wells. In this study:

Step 1: First a model for the reservoir was defined for streamline simulation.

Step 2: Results of M.Sayyafzadeh et al (2010) for finding the location of infill wells by using streamline simulation were investigated. 
Step 3: Based on the results of step 2, four infill wells in a model were defined to investigate infill drilling scenario in order to optimize oil recovery factor.

Step 4: For each infill well 6 scenarios by defining wells vertically and horizontally were investigated to find the best situation and the best layer for horizontal wells with the highest oil recovery factor.

Step 5: Totally 34 scenarios were defined and were tested by Streamline simulation method and then oil recovery factors were compared to the base model to select the best scenario.

Figure 2 shows the procedure of the simulation:

1. Estimation of basic field characteristics and production parameters such as oil rate, water rate, water cut, solution gas rate, bottom hole pressure and field average pressure.

2. Using streamline simulation for finding rate between producers and injectors and relation between water injection rate and oil production rate for calculating the effect of each injectors on producers to optimize field oil production.

3. Based on streamlines output from software after the simulation, several senarios were defined such as infill drilling and finding the location of infill well.

4. After testing and simulation these changes, if they improve the results, they would be performed otherwise another scenario will be defined.

5. If a change would be approved, based on new model new streamlines will be created.

6. This procedure will be continued unless some economical limitation cease that.

\section{Finding infill wells locations}

In first step, after building the model with heteroginity and faults, to predict for 3683 days production by using FrontSim and without any especial scenario, the recovery factor was 20.02 $\%$. Figure 1 shows streamlines and location of the wells in FloViz software. Based on the figure 2, for defining first scenario, Infill drilling was tested for this field. By using of this method the best location for drilling of new well could be found. Sayyafzadeh et al (2010) 
investigated locations of infill wells by using Streamline Simulation which new producers should be drilled in sections of the reservoir where the streamline density is low and the oil saturation is high. Although streamlines tend to cluster in regions of high flow and are sparsely distributed in low-permeability regions (Gupta et al., 2007), two new producers for this field were tested in high and low streamline density, the oil recovery factor were $23.98 \%$ and 24.06 $\%$ respectively, therefore same results for selecting the location of infill wells as Sayyafzadeh et al (2010) had been gotten by using streamline simulation. In addition to suitable rock characteristics such as porosity, permeability and NTG, places where streamlines are not dense and upswept oil saturation is high, are proper for drilling new wells. Based on streamlines in figure 1 and by considering enough space between wells, in order to have no interference in their drainage area, four new producers (P10, P11, P12 and P13 ) were defined in the model to produce like other producers with the same conditions in the field and again simulation by FrontSim was done. In this work several scenarios were defined in order to maximize oil production of the reservoir. First these wells were defined vertically and perforated in five layers and ran the simulator, the oil recovery factor of the field was 32.63\%.

\section{Testing infill horizontal wells}

In next step, in order to investigate infill horizontal wells, each horizontal well was considered separately which was perforated in one layer and then the recovery factor was calculated to find that which layer affects field oil production more for each infill well, even several orientations for legs of horizontal wells were investigated to find the best orientation; Hence the best layer and the best orientation which maximize the recovery factor was chosen. Results of this step are summarized in table 1 which shows four infill wells P10, P11, P12 and P13 and their recovery factor in each layer ( layer 1 to layer 5) were calculated to best layer will be selected, then these wells were considered vertically and their recovery factors were calculated for this state too. Figure 4 shows the streamlines of well P10 in horizontal and vertical 
directions as an example. By using streamline simulation, numbers of scenario defining for drilling infill wells will be decreased since it is known which parts of reservoir are swept less unlike finite difference simulation.

\section{Testing infill horizontal and vertical wells}

Up to this stage, the location of infill wells and recovery factors if infill wells will be drilled vertically or horizontally and even in which layer should be perforated to have more oil production were found, then 10 scenarios were defined with considering 4 new producers all together in a model, in every scenario some wells vertically and some wells horizontally were investigated but in their best layer with maximum oil recovery factor which it is known from the previous step and after simulation, the oil recovery factor for every scenario was calculated in order to optimize oil production for the reservoir. Results and these 10 scenarios are summarized in table 2-A and 2-B.

\section{Result and Discussions}

Water production problem in oil and gas fields can be solved by using streamline simulation by adjusting injector's rate in every scenario to maximize oil production instead of maximizing water injection. In order to have better water flooding management, it is used to know that how much injectors supporting producers for field oil production. Well allocation factor (WAF) is a unique parameter which has been calculated just by streamline simulation. For instance producer P13 after 1826 days is supported from two injectors (I2 and I3) with $1.18 \%$ and 0.727\% and also $98.1 \%$ from aquifer, therefore for well P13, by considering the leg of horizontal well toward the aquifer, oil production will be increased obviously, therefore based on these information, all producers and injectors can be optimized, for example converting producers with low efficiency to injectors or increasing injection rate in injectors with high efficiency and decreasing rate in low efficiency injectors. Other advantages of WAF especially in water flooding is balancing wells patterns, infill drilling, optimization rate injection , sweep 
efficiency and injection efficiency. In this paper infill drilling is analyzed. Figure 1 shows that streamlines in a section of the reservoir change their direction suddenly which caused by fractures or faults , since the reservoir is not fractured hence this place should be a fault which based on streamlines and due to high water saturation along these streamlines, it acts like a new aquifer for wells which support them, especially well P13 after defining infill drilling scenario which its well allocation factor $98.1 \%$ between Aquifer and P13 and streamlines ended to P13 prove it . The location of the fault is shown in figure 1.

After testing 10 scenarios with four infill wells simultaneously in a model by FrontSim software, Scenario 10 which was defined in table 2-B that P10-P12-P13 were horizontal and P10 was vertical, had the maximum oil recovery factor among other scenarios by using Streamline simulation method comparing to the base model, since the best state was chosen regarding to the highest oil recovery factors for each infill well from table 1, and figure 5 shows diagrams of field oil production rate and field oil production total for best scenario (scenario 10). Consequently field water cut decreased, and finally field pressure with four new infill producers decreased overally and sometimes it raised during production period after infill wells became active in the model. At last to compare CPU time between FrontSim and Eclipse black oil or Streamline simulation and finite difference method, just scenario 10 was ran with these simulators with the same solver equations and conditions, the result shows the huge difference between their CPU time and indicates that FrontSim approximately $36.42 \%$ is faster than Eclipse 100 for this model since in Streamline simulation method saturation equations solve in one direction along streamlines but in finite difference method saturation equations solve in 3D and simultaneously so it spends more time.

\section{Conclusion}

Due to high speed of Streamline simulation especially for complex reservoirs with thousands grids, reservoir engineers have this opportunity to test and run several scenarios in minimum 
run time, so by testing several scenarios, one could choose the best scenario with the highest efficiency. In addition; by using streamlines, unswept sections of the reservoir and the best location of infill wells could be found. In this study, after testing 20 scenarios to find the best layer for four infill horizontal wells in each layer besides 4 scenarios for infill drilling these wells vertically 10 scenarios were defined to consider four infill wells together in a model, hence 34 scenarios were investigated totally, as a result the oil recovery factor increased from $20.02 \%$ from the base model to $32.75 \%$ by considering infill wells horizontally and vertically, furthermore field water cut decreased too in order to optimize the field oil production. Additionally, when the leg of horizontal well is toward the injectors or the aquifer which streamlines show it clearly,the oil recovery factor will be increased and the location of faults could be recognized using streamline simulation.

\section{Reference}

J. Hou and S.K Zhang, 2007.A Streamline-Based Model for Potentially Prediction of Enhance Oil Recovery, SPE 105246.

P. Samier, L. Quettier, M. Thiele, 2001. Applications of Streamline Simulations to Reservoir Studies, SPE 66362.

Marco R. Thiele, 2001, StreamSim Technologies, Inc. Streamline Simulation. 6th International Forum on Reservoir Simulation, Schloss Fuschl, Austria.

A. D. Gupta, M.J. King (2007). Streamline Simulation: Theory and Practice. Texas: SPE Textbook Series, Richardson. Texas

Kalantariasi, A., Farhadi, I., Nasriani, H.R., On the accuracy of dimensionless inflow performance relationships for gas wells. (2013) Society of Petroleum Engineers - North Africa Technical Conference and Exhibition 2013, NATC 2013, 1, pp. 159-172. 
M.Sayyafzadeh, P.Pourafshary, F.Rashidi, 2010. Increasing Ultimate Oil Recovery And Converting Weak Production Wells To Injection Wellsusing Streamline Simulation, SPE 132125.

Nasiri Ghiri, M., Nasriani, H.R., Sinaei, M., Najibi, S.H., Nasriani, E., Parchami, H., Gas Injection for Enhancement of Condensate Recovery in a Gas Condensate Reservoir. (2015) Energy Sources, Part A: Recovery, Utilization and Environmental Effects, 37 (8), pp. 799-806. DOI: 10.1080/15567036.2011.596901

Nasriani, H.R., Asadi, E., Nasiri, M., Khajenoori, L., Masihi, M., Challenges of fluid phase behavior modeling in Iranian retrograde gas condensate reservoirs. (2015a) Energy Sources, Part A: Recovery, Utilization and Environmental Effects, 37 (6), pp. 663-669. DOI: 10.1080/15567036.2011.594865

Nasriani, H.R., Borazjani, A.A., Iraji, B., MoradiDowlatAbad, M., Investigation into the effect of capillary number on productivity of a lean gas condensate reservoir. (2015b) Journal of Petroleum Science and Engineering, 135, pp. 384-390. DOI: 10.1016/j.petrol.2015.09.030

Nasriani, H.R., Borazjani, A.A., Sinaei, M., Hashemi, A., The effect of gas injection on the enhancement of condensate recovery in gas condensate reservoirs: A comparison between a synthetic model and PVT cell results. (2014) Petroleum Science and Technology, 32 (5), pp. 593-601. DOI: 10.1080/10916466.2011.596890

V.Dehdari, B.Aminshahidy, A.Tabatabaei-Nejad, 2008. Well Spacing and Recovery Optimization of One Iranian Oil Fields by Using Streamline and Reservoir Simulation, SPE 112985.

Zareenejad, M.H., Kalantari Asl, A., Nasriani, H.R., Zargar, Gh. Analysis and comparison of decline models: A field case study of a naturally fractured gas condensate reservoir. 
(2015) Energy Sources, Part A: Recovery, Utilization and Environmental Effects, 37 (4), pp. 392-400. DOI: 10.1080/15567036.2011.576409 
Table 1 : Infill Drilling Models In Horizontal And Vertical Directions

\begin{tabular}{|c|c|c|c|c|c|c|c|}
\hline \multicolumn{2}{|c|}{ Remark } & \multicolumn{2}{|c|}{ Vertical Wells } & \multicolumn{4}{|c|}{ Horizontal Wells } \\
\hline $\begin{array}{c}\text { NUMBER OF } \\
\text { PERFORATION }\end{array}$ & $\begin{array}{c}\text { INFILL } \\
\text { DRILLING } \\
\text { DATE }\end{array}$ & $\begin{array}{c}\text { RECOVERY } \\
\text { FACTOR } \\
(\%)\end{array}$ & VERTICAL & REMARK & $\begin{array}{l}\text { RECOVERY } \\
\text { FACTOR }(\%)\end{array}$ & HORIZONTAL & $\begin{array}{c}\text { INFILL } \\
\text { DRILING }\end{array}$ \\
\hline \multirow{3}{*}{$\begin{array}{l}5 \text { Perforation In } \\
\text { Horizontal Wells }\end{array}$} & \multirow{5}{*}{$\begin{array}{c}\text { AFTER } \\
1461 \\
\text { DAYS }\end{array}$} & \multirow{5}{*}{23.72} & \multirow{5}{*}{$P 10$} & & 24.14 & Layer-1 & \multirow{5}{*}{$P 10$} \\
\hline & & & & & 20.67 & Layer-2 & \\
\hline & & & & & 23.72 & Layer-3 & \\
\hline \multirow{2}{*}{$\begin{array}{l}5 \text { Perforation In } \\
\text { Vertical Wells }\end{array}$} & & & & MAX & 24.18 & Layer-4 & \\
\hline & & & & & 23.66 & Layer-5 & \\
\hline \multirow{5}{*}{$\begin{array}{l}5 \text { Perforation In } \\
\text { Vertical Wells }\end{array}$} & \multirow{5}{*}{$\begin{array}{l}\text { AFTER } \\
2099 \\
\text { DAYS }\end{array}$} & \multirow{5}{*}{22.00} & \multirow{5}{*}{$P 11$} & & 21.93 & Layer-1 & \multirow{5}{*}{$P 11$} \\
\hline & & & & & 20.37 & Layer-2 & \\
\hline & & & & & MB error & Layer-3 & \\
\hline & & & & & 22.02 & Layer-4 & \\
\hline & & & & MAX & 22.12 & Layer-5 & \\
\hline \multirow{3}{*}{$\begin{array}{l}5 \text { Perforation In } \\
\text { Horizontal Wells }\end{array}$} & \multirow{5}{*}{$\begin{array}{c}\text { AFTER } \\
1247 \\
\text { DAYS }\end{array}$} & \multirow{5}{*}{23.56} & \multirow{5}{*}{$P 12$} & MAX & 23.46 & Layer-1 & \multirow{5}{*}{$P 12$} \\
\hline & & & & & MB error & Layer-2 & \\
\hline & & & & & MB error & Layer-3 & \\
\hline \multirow{2}{*}{$\begin{array}{l}5 \text { Perforation In } \\
\text { Vertical Wells }\end{array}$} & & & & & 23.36 & Layer-4 & \\
\hline & & & & & 23.37 & Layer-5 & \\
\hline \multirow{5}{*}{$\begin{array}{l}5 \text { Perforation In } \\
\text { Vertical Wells }\end{array}$} & \multirow{5}{*}{$\begin{array}{c}\text { AFTER } \\
1826 \\
\text { DAYS }\end{array}$} & \multirow{5}{*}{22.93} & \multirow{5}{*}{$P 13$} & & 22.91 & Layer-1 & \multirow{5}{*}{$P 13$} \\
\hline & & & & & 20.59 & Layer-2 & \\
\hline & & & & MAX & 22.93 & Layer-3 & \\
\hline & & & & & 22.84 & Layer-4 & \\
\hline & & & & & 22.86 & Layer-5 & \\
\hline
\end{tabular}


Table 2-A : Simulation Results Of Infill Drilling

\begin{tabular}{|c|c|c|c|c|}
\hline RATING & $\begin{array}{c}\text { RECOVERY } \\
\text { FACTOR }(\%) \\
\end{array}$ & WELLS MODEL & SCENARIO & ROW \\
\hline- & 20.02 & P1-P2-P3-P4-P5-P6-P7-P8-P9 & BASE MODEL & 0 \\
\hline & & & & \\
\hline \multirow{4}{*}{$*$} & \multirow{4}{*}{32.56} & P 10 - VERTICAL & \multirow{4}{*}{ SCENARIO 1} & \multirow{4}{*}{1} \\
\hline & & P 11 - VERTICAL & & \\
\hline & & P12 - HORIZONTAL - LAYER 1 & & \\
\hline & & P 13 - VERTICAL & & \\
\hline & & & & \\
\hline \multirow{4}{*}{$* *$} & \multirow{4}{*}{32.62} & P 10 - VERTICAL & \multirow{4}{*}{ SCENARIO 2} & \multirow{4}{*}{2} \\
\hline & & P11 - HORIZONTAL - LAYER 5 & & \\
\hline & & P 12 - VERTICAL & & \\
\hline & & P13 - HORIZONTAL - LAYER 3 & & \\
\hline & & & & \\
\hline \multirow{4}{*}{$* *$} & \multirow{4}{*}{32.62} & P10 - HORIZONTAL - LAYER 4 & \multirow{4}{*}{ SCENARIO 3} & \multirow{4}{*}{3} \\
\hline & & P 11 - VERTICAL & & \\
\hline & & P 12 - VERTICAL & & \\
\hline & & P 13 - VERTICAL & & \\
\hline & & & & \\
\hline \multirow{4}{*}{$* *$} & \multirow{4}{*}{32.62} & P10 - HORIZONTAL - LAYER 4 & \multirow{4}{*}{ SCENARIO 4} & \multirow{4}{*}{4} \\
\hline & & P11 - HORIZONTAL - LAYER 5 & & \\
\hline & & P 12 - VERTICAL & & \\
\hline & & P13 - HORIZONTAL - LAYER3 & & \\
\hline & & & & \\
\hline \multirow{4}{*}{$* *$} & \multirow{4}{*}{32.64} & P 10 - VERTICAL & \multirow{4}{*}{ SCENARIO 5} & \multirow{4}{*}{5} \\
\hline & & P 11 - VERTICAL & & \\
\hline & & P 12 - VERTICAL & & \\
\hline & & P 13 - VERTICAL & & \\
\hline
\end{tabular}


Table 2-B : Simulation Results Of Infill Drilling

\begin{tabular}{|c|c|c|c|c|}
\hline RATING & $\begin{array}{c}\text { RECOVERY } \\
\text { FACTOR ( \% ) }\end{array}$ & WELLS MODEL & SCENARIO & ROW \\
\hline \multirow{4}{*}{$* * *$} & \multirow{4}{*}{32.68} & P 10 - VERTICAL & \multirow{4}{*}{ SCENARIO 6} & \multirow{4}{*}{6} \\
\hline & & P11 - HORIZONTAL - LAYER 5 & & \\
\hline & & P12 - HORIZONTAL - LAYER 1 & & \\
\hline & & P13 - HORIZONTAL - LAYER3 & & \\
\hline \multirow{4}{*}{$* * *$} & \multirow{4}{*}{32.69} & P10 - HORIZONTAL - LAYER 4 & \multirow{4}{*}{ SCENARIO 7} & \multirow{4}{*}{7} \\
\hline & & P 11 - VERTICAL & & \\
\hline & & P12 - HORIZONTAL - LAYER 1 & & \\
\hline & & P 13 - VERTICAL & & \\
\hline \multirow{4}{*}{$* * * *$} & \multirow{4}{*}{32.73} & P10 - HORIZONTAL - LAYER 4 & \multirow{4}{*}{ SCENARIO 8} & \multirow{4}{*}{8} \\
\hline & & P11 - HORIZONTAL - LAYER 5 & & \\
\hline & & P12 - HORIZONTAL - LAYER 1 & & \\
\hline & & P 13 - VERTICAL & & \\
\hline & & & & \\
\hline \multirow{4}{*}{$* * * *$} & \multirow{4}{*}{32.74} & P10 - HORIZONTAL - LAYER 4 & \multirow{4}{*}{ SCENARIO 9} & \multirow{4}{*}{9} \\
\hline & & P11 - HORIZONTAL - LAYER 5 & & \\
\hline & & P12 - HORIZONTAL - LAYER 1 & & \\
\hline & & P13 - HORIZONTAL - LAYER3 & & \\
\hline & & & & \\
\hline \multirow{4}{*}{$* * * * *$} & \multirow{4}{*}{32.75} & P10 - HORIZONTAL - LAYER 4 & \multirow{4}{*}{ SCENARIO 10} & \multirow{4}{*}{10} \\
\hline & & P 11 - VERTICAL & & \\
\hline & & P12 - HORIZONTAL - LAYER 1 & & \\
\hline & & P13 - HORIZONTAL - LAYER3 & & \\
\hline
\end{tabular}




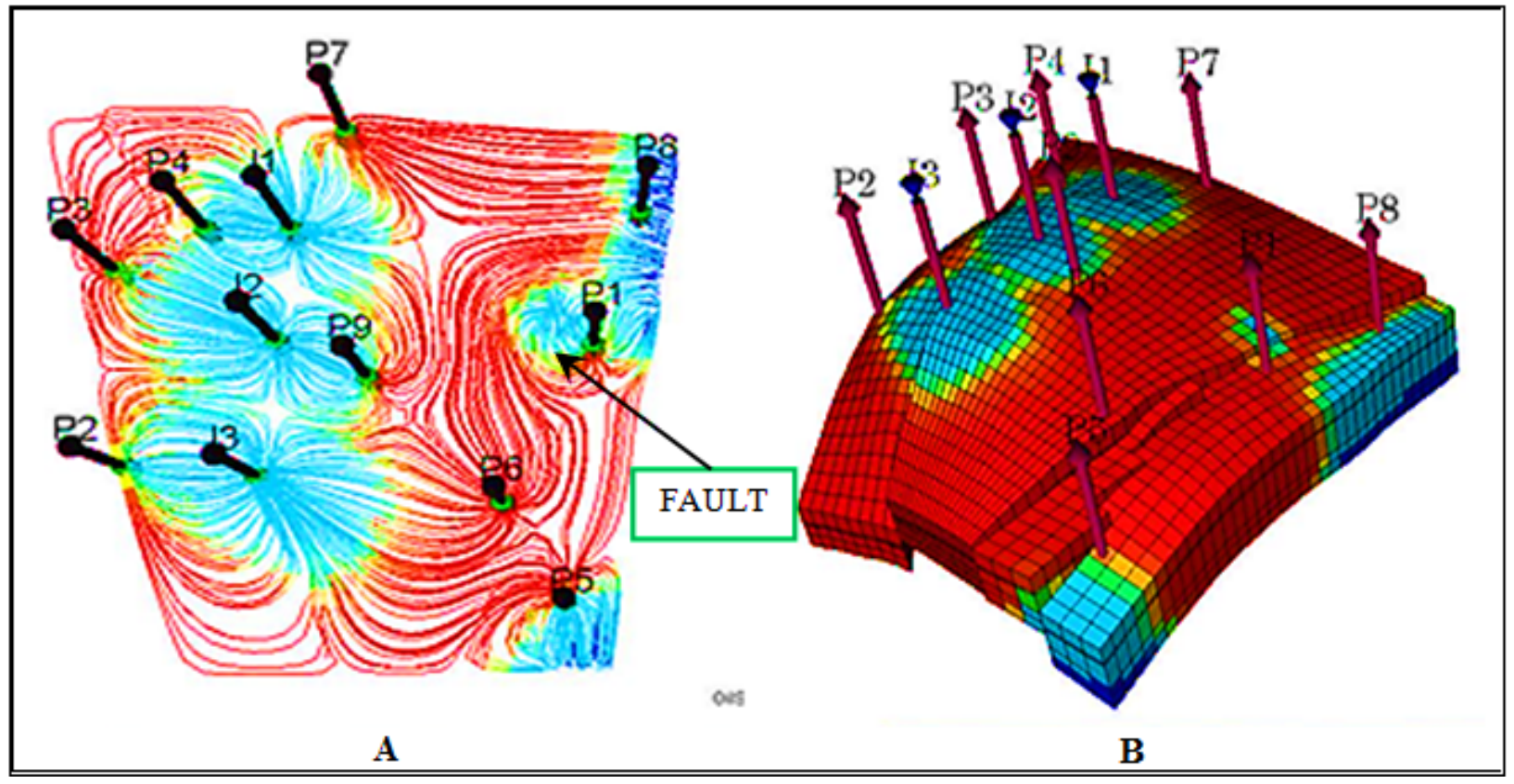

Figure 1: Base Model and Fault Location, A) Streamline Model, B) Full Field 3D Model Grid 


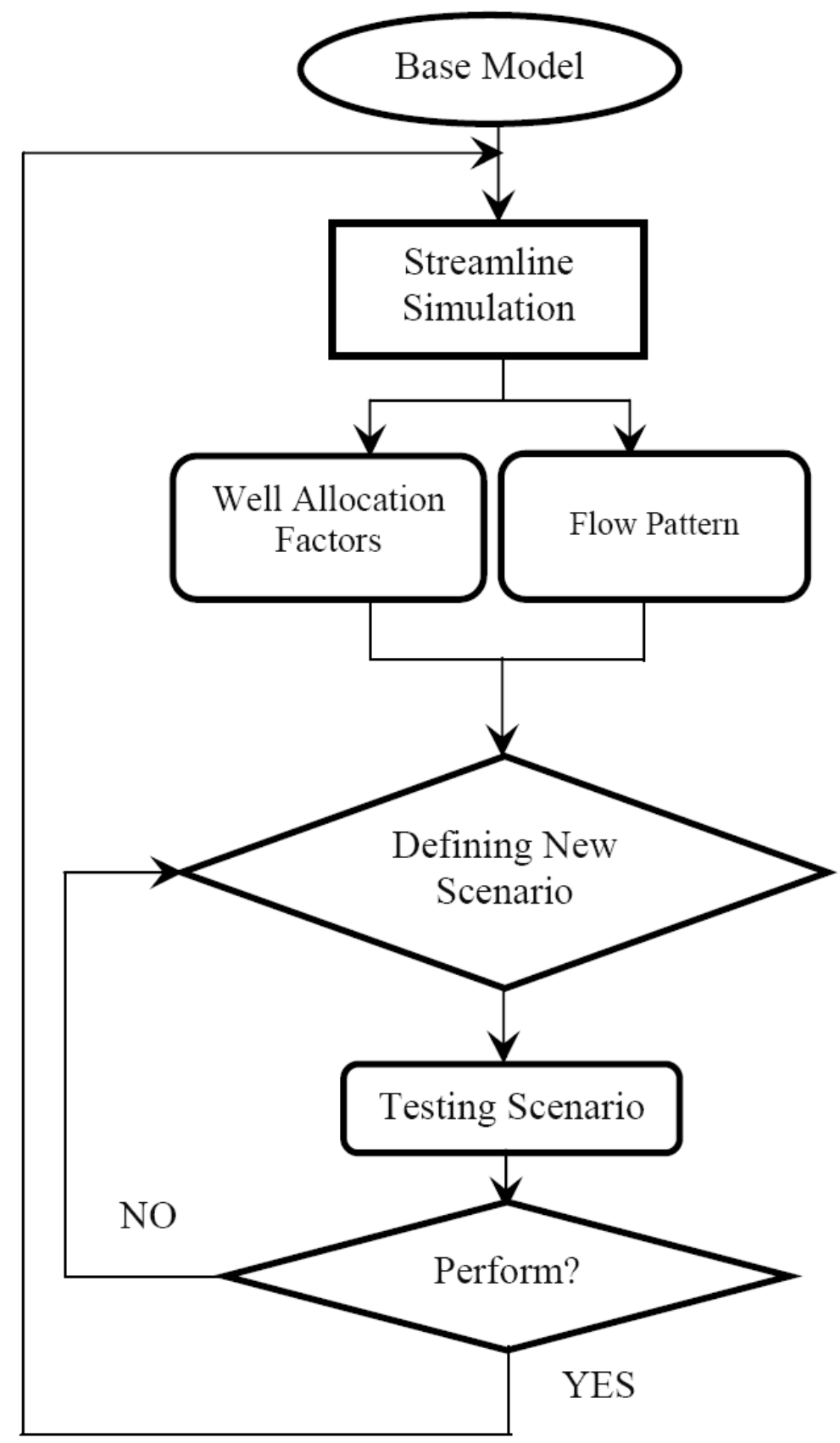

Figure 2: Flowchart of the Simulation 


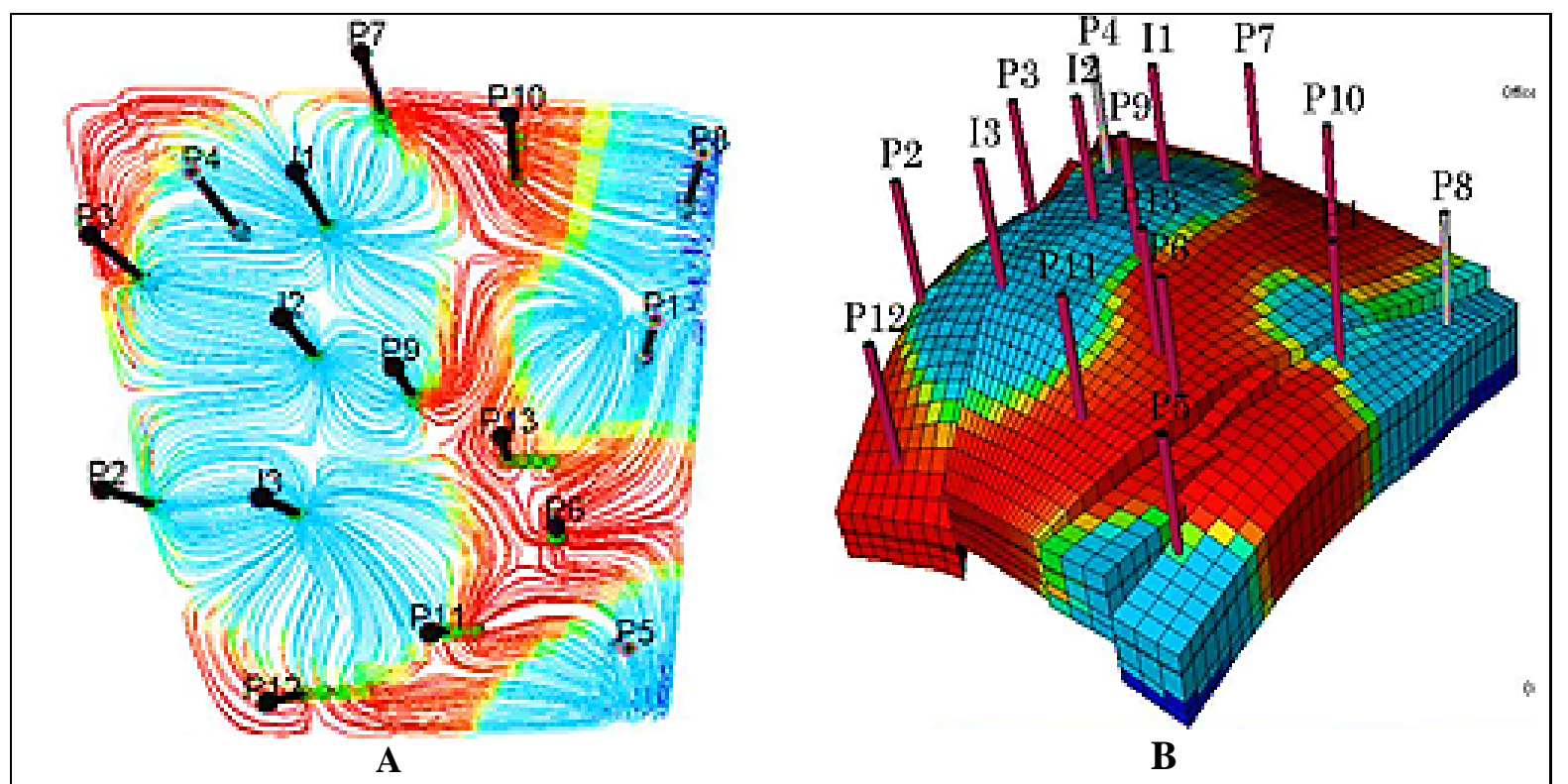

Figure 3: The Best Scenario Model (Scenario 10), A) Streamline Model, B) Full Field 3D Model Grid 


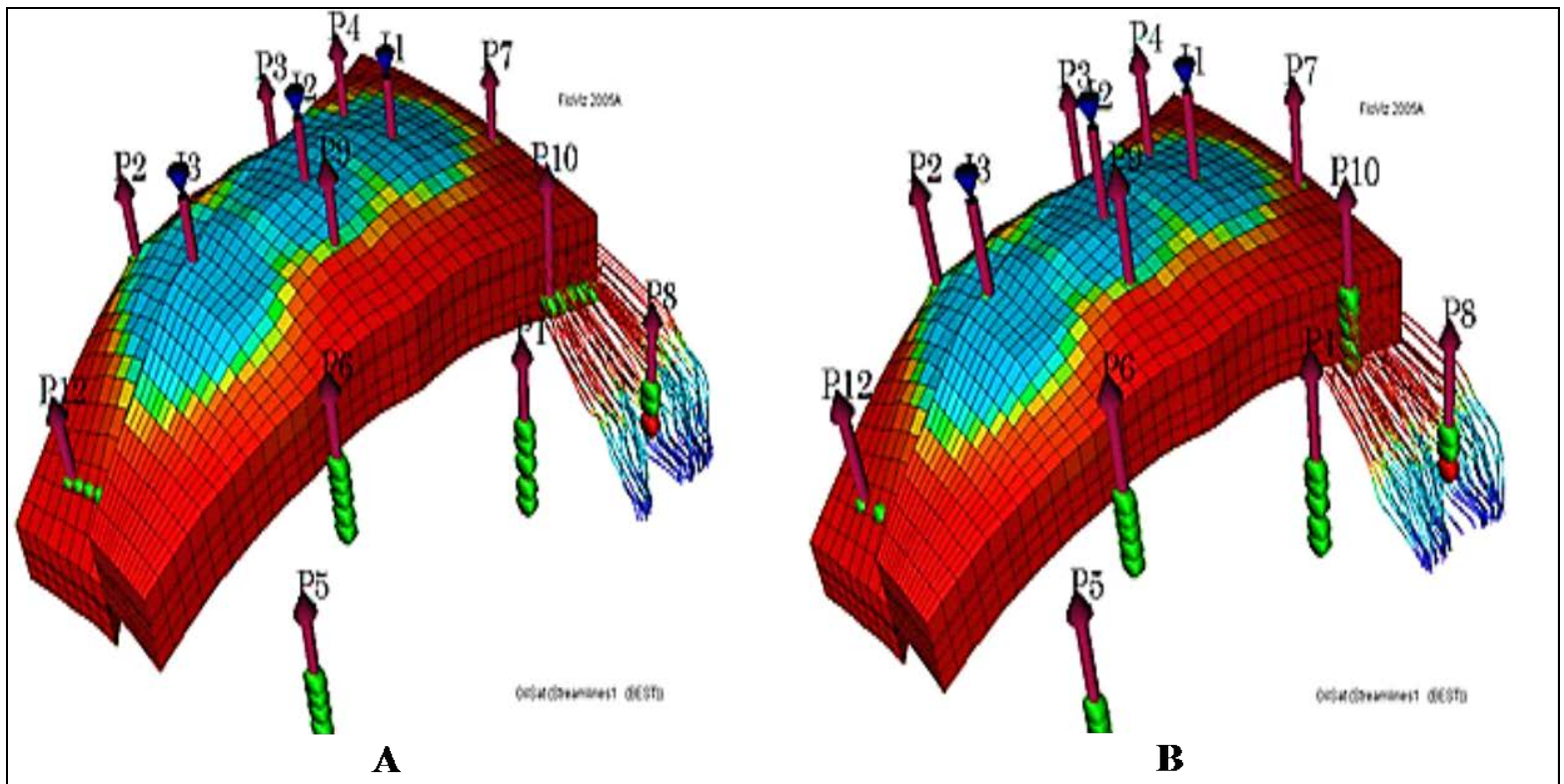

Figure 4: Streamlines Of Well P10. A) Horizontal Direction, B) Vertical Direction 


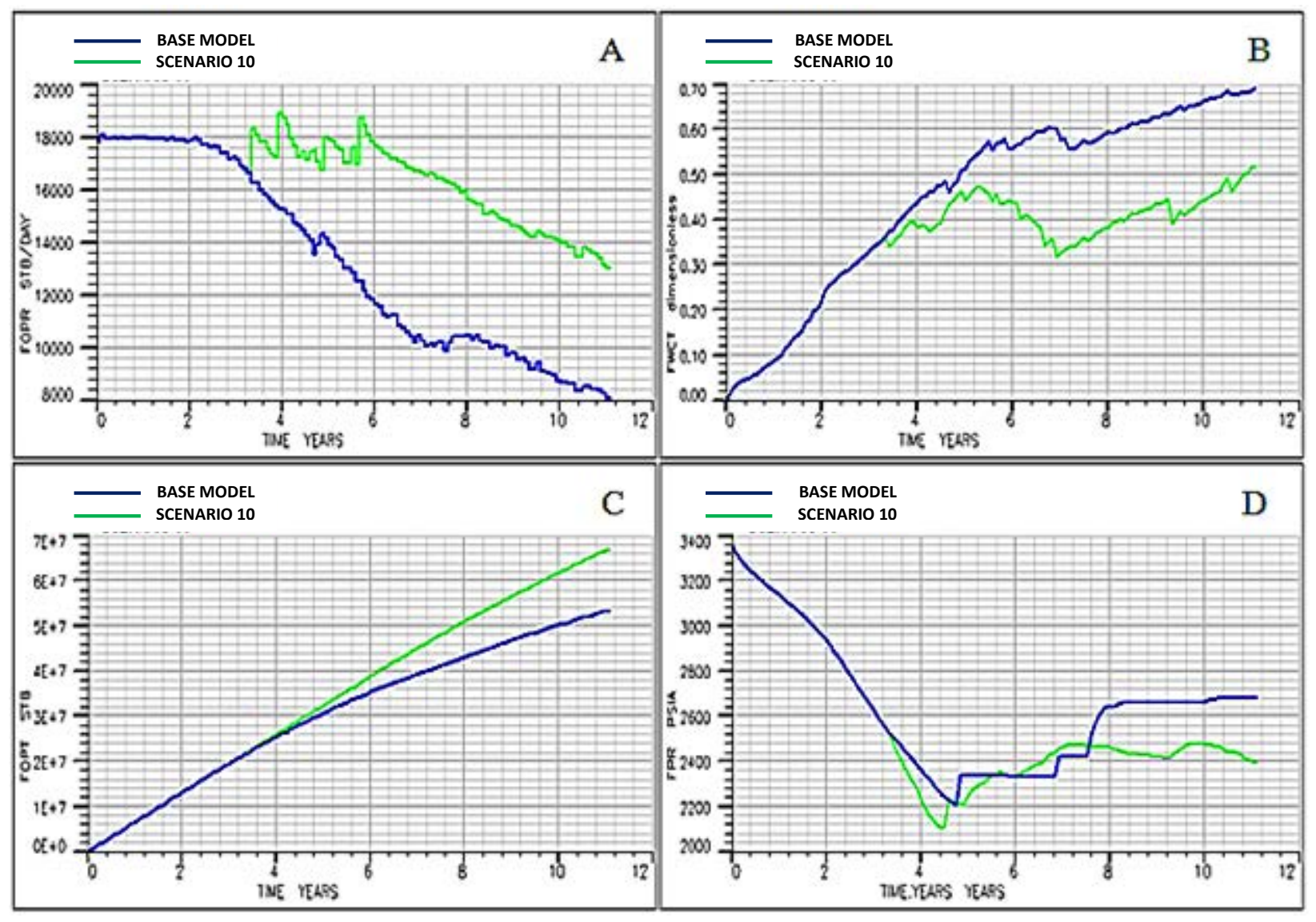

Figure 5: Compare results of simulation between the base model and the best scenario (SCENARIO 10) - A) Field Oil Production Rate, B) Field Water Cut, C) Field Oil Production Total, D) Field Pressure. 